\title{
Aerothermodynamic Analysis of a Blunt Body with Forward Facing Cavity and Opposing Jet Combination
}

\author{
Mahesh Kavimandan \\ Cyient Ltd. (Hyderabad)
}

\author{
Bassetti Chandrasheker \\ Cyient Ltd. (Hyderabad)
}

\begin{abstract}
In high-speed travel such as space travel, the heat produced on the Re-Entry body due to frictional effects is of major concern. Several studies and research have been done to overcome this problem with new ideas and theories. This paper deals with the reduction of aero thermodynamic heating due to frictional force or drag forces on the surface of the body. In this paper, various combinations of Forward Facing Cavity are taken along with opposing Jet stream with different $r / d$ ratio where $d$ represents the cavity depth and $r$ represents the radius of the cavity in a blunt body using different pressure and location of the jet stream. We have analyzed the model at Mach 6.2 i.e. supersonic condition at $11 \mathrm{~km}$ of altitude with the help of the CFD software, Ansys and using its two-module Gambit for meshing and Fluent for solving. Later, the results are compiled and compared between a simple blunt body and with various combinations of the cavity and its depth. The best result is considered to be the one in which the most heat reduction is attained.
\end{abstract}

Keywords—Blunt Body; Forward Facing Cavity; Opposing Jet

\section{INTRODUCTION}

The research and development of hypersonic vehicles such as interceptor missiles, hypersonic aircraft, and hypervelocity projectiles are designed to withstand heat loads at hypersonic Mach number and strike enemy targets swiftly. As new spacecraft is designed, the latest traditional measures for thermal protection such as ablation is tough to satisfy new designs. For example, let's consider the reusable requirement. The combination of high speed and dense atmosphere can detrimentally increase the aerodynamic heating at the nose section for such vehicles. The severe heating of the nose changes the aerodynamics including shape and size, also damaging the electronic hardware or payload that is contained inside the nose section. So vehicles should be designed to withstand such aerothermal loads at the nose cone.

A simple passive design that has been investigated now, especially for the heat reduction is on missile forward cones by introducing a forward-facing cavity located at the stagnation region of a blunt vehicle. It has been established that the flowfield around a concave nose is similar to the flowfield around a flat-faced cylinder. Theoretically, a flat-faced cylinder has minimum stagnation-point heat-transfer rates because of the radius of the curvature at the nose is infinite, as the heattransfer rate is inversely proportional to the square root of the nose radius.

Cooper measured the heat transfer rates at the stagnation point of a concave hemispherical nose at Mach numbers of 1.98 and 4.95 [1]. He observed that the steady flow heat-transfer coefficients were 20 to $50 \%$ of the heat-transfer coefficient associated with the convex nose shape. Hopko and Strauss investigated on a $30 \mathrm{deg}$ blunted cone with a concave nose shape indicated that the heating at the stagnation point is reduced to $1 / 8$ of the heating for convex noses at Mach number of 8 [2]. Stallings and Burbank also observed a significant reduction at the position of stagnation-point heat-transfer rates for concave hemispherical noses for steady-state flow conditions compared to convex nose shapes [3]. A sufficiently deep forward-facing rectangular or cylindrical cavity in hypersonic flow acts like an organ pipe, and the flow inside the cavity oscillates at its natural frequency. The oscillation of the stagnant cavity fluid causes the oscillation of the bow shock wave, which in turn produces the cooling effect.

A study on the oscillation of bow shock waves and corresponding heat transfer rates for blunt cones with forward facing cavity was done at Mach 10 by Sambamurthi et al. Heubner and Utreja [4]. It was found that for appropriately deep cavities, the local heat fluxes were reduced on the surface when the longitudinal pressure oscillations induce large bow shock oscillations within the cavity. A significant study was done on the heat flux to a blunt nose projectile armed with nose cavity at Mach 4.5 by Saravanan et al [5] and Lu and Liu, Seiler et al. and the results showed that the deepest cavity has the smallest heat flux [6]. A reduction of 35-40\% surface convective heat transfer rates for a missile-shaped body with a nose cavity located in the stagnation region at a free-stream Mach number 8. Lu and Liu proved that deeper the cavity, the smaller the heat flux, and the mean fluxes increases along the body surface to reach a peak value near the sharp edge then fall sharply.

The use of opposing jet from the top of the blunt body caused a reduction of aerodynamic heating which was investigated experimentally and numerically. This proved to be quiet effective at the nose of the blunt body. Hayashi et al showed the effects of the ratio of stagnation pressure of opposing jet to free stream on the reduction of aerodynamic heating [7]. The heat flux decreases at each point of the nose surface, as the pressure ratio increases. Using the high precision simulation of Navier Stokes equations, a study on the influence of free Mach number, jet Mach number, and angle of attack on the reduction of drag coefficient was done. The opposing jet through an extended nozzle was proposed by Tamada et al. [8]. The performance was demonstrated using CFD analysis. The shape of this device is similar to blowpipes used by glass blowers. The extended nozzle is intended to 
enlarge the recirculation region even by a weak opposing jet. No study could be done with opposing jet through an extended nozzle in high enthalpy hypersonic flow. Naoki Morimoto et al performed a shock tunnel test campaign which showed the capability to alleviate aerodynamic heating by the opposing jet through the extended nozzle [9].

Introduction of lateral jets from the tip of the spike was by Jiang et al. The lateral jet pushes the conical shock wave originating from the tip of the spike away from the blunt body so that it reduces the peak value of pressure and heat flux around the reattachment point [10]. Experiments were done for the effects of opposing jets in both stable and unstable conditions. The results showed the effect of opposing has a significant decrease in surface heat flux and proved to be effective on aerodynamic heat reduction around a stagnation region of a blunt body. Hutt et al experimentally showed that there is a significant reduction of drag by using a structural spike extending from the nose of a blunt body flying at a supersonic speed [11]. Rajesh Yadav et al. have investigated the aerodynamic heating of a hemisphere-cylinder with a forward-facing ellipsoid and parabolic cavity at the nose in the atmosphere. A wide range of ellipsoid and parabolic cavities of varying depths were used. The simulation results suggest that the stagnation-point heat flux and the total heat-transfer rates to the blunt body can be favorably reduced by the introduction of ellipsoid [12] and parabolic cavities [13].

\section{A. FORWARD FACING CAVITY}

Hypersonic vehicles experience high kinetic energy due to its high speed. This high kinetic energy creates high temperature which affects the vehicle. This produces a huge loss to the hypersonic vehicle which leads to damage in a structure, unwanted change in aerodynamics and also damages the avionics and payload at the nose of the vehicle. Aerodynamic heating is one reason which may cause damage to the vehicle. There are many techniques to reduce aerodynamic heating. One of the techniques is by using a forward facing cavity.

Forward facing cavity is a cavity made at the front of the nose of the vehicle. This cavity helps in creating a recirculation region which plays an important role. It acts like a cooling effect which reduces the aerodynamic heating. The flow inside the cavity oscillates at its natural frequency causing the bow shock wave oscillation which produces a cooling effect. Many types of research and investigations took place for the effect of a forward facing cavity. A part of this paper is to analyze the effects of a forward facing cavity on a blunt body flying at hypersonic speeds. Previous results proved that deeper the cavity more is the heat reduction.

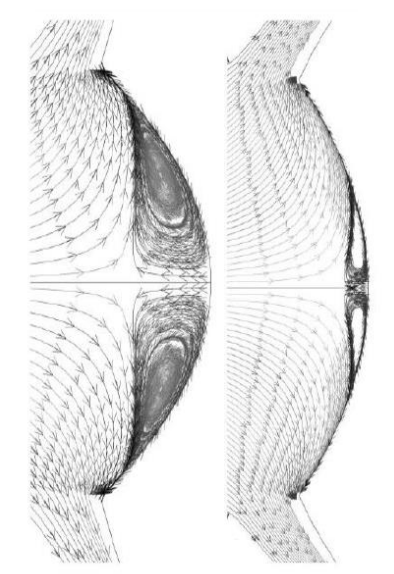

Fig. 1: Forward facing cavity

\section{B. OPPOSING JET TECHNIQUE}

Another technique to reduce aerodynamic heating is the use of opposing jet techniques. The total pressure of the opposing jet is an important parameter. The coolant gases like $\mathrm{N}_{2}$ and $\mathrm{He}$ (inert gases) are used. These are injected which helps in creating a recirculating region. This recirculating region then cools down the heating produced at the nose of the vehicle.

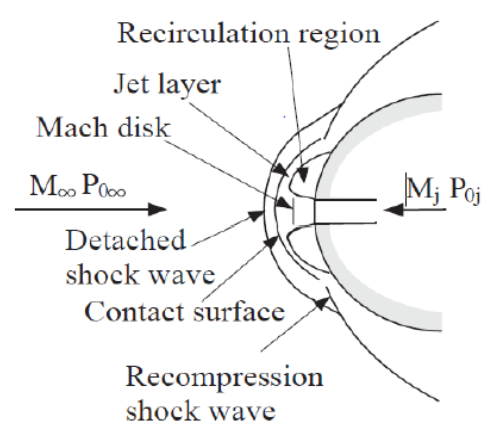

Fig. 2: Opposing jet on a blunt body

In this paper, a CFD analysis is done on a blunt body alone, a blunt body having a forward facing cavity and a blunt body having a forward facing cavity with an opposing jet. The combinational thermal protection system reduces much of the aerodynamic heat which is proved in this paper.

\section{CFD ANALYSIS}

Computational fluid dynamics (CFD) uses numerical methods and algorithms to solve and analyze problems involving fluid flows. The CFD analysis we have used is ANSYS. In this paper, we have used Gambit for meshing and FLUENT as a solver.

\section{A. PREPROCESSING}

This consists of two sections

i. Creation of Geometry

ii. Mesh Generation 


\section{B. GEOMETRY}

a) Gambit software is chosen to create geometry and to mesh it. Firstly, a geometry tool pad is selected and a baseline is created using line option having a length of $70 \mathrm{~mm}$.

b) To create a blunt nose, a curve of radius $20 \mathrm{~mm}$ is drawn in front of the baseline and this makes the base body to the problem statement.

c) A wind tunnel section is created around the base body with required dimensions, which is the domain of geometry.

d) Zone assignment i.e. naming the inlet pressure farfield, outlet pressure far-field, wall and body as required is done.

e) This step is repeated to create the geometry of various dimensions, having different $\mathrm{r} / \mathrm{d}$ ratio for the cavity to compare results for the problem statement.

f) Similarly, these steps are repeated to create an opposing jet in the blunt body, with different $\mathrm{r} / \mathrm{d}$ ratio.

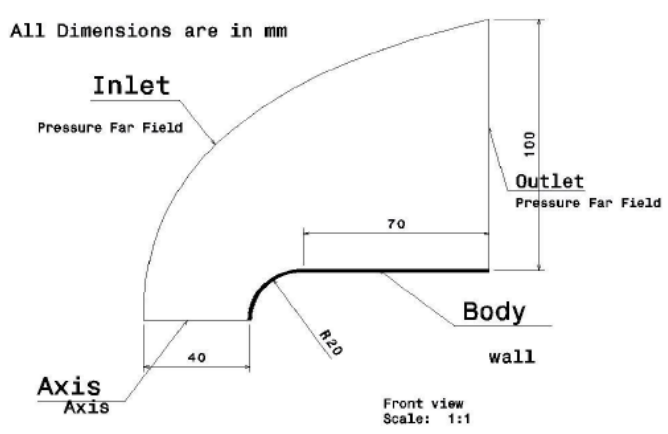

Fig. 3: Geometry of a blunt body

The above geometry is for a blunt body. Its dimensions are mentioned above. The radius of the nose of the blunt body is $20 \mathrm{~mm}$ and length is $70 \mathrm{~mm}$.

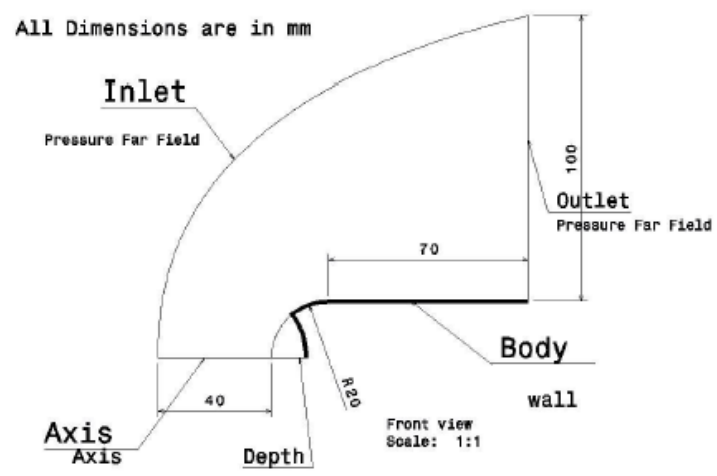

Fig. 4: Blunt Body with Forward Facing Cavity
The above geometry has a cavity of varying depth or $\mathrm{r} / \mathrm{d}$ ratio. This paper deals with different $\mathrm{r} / \mathrm{d}$ ratios 1, 2, 2.5 and different depths of $4 \mathrm{~mm}, 6 \mathrm{~mm}, 8 \mathrm{~mm}$ and $10 \mathrm{~mm}$.

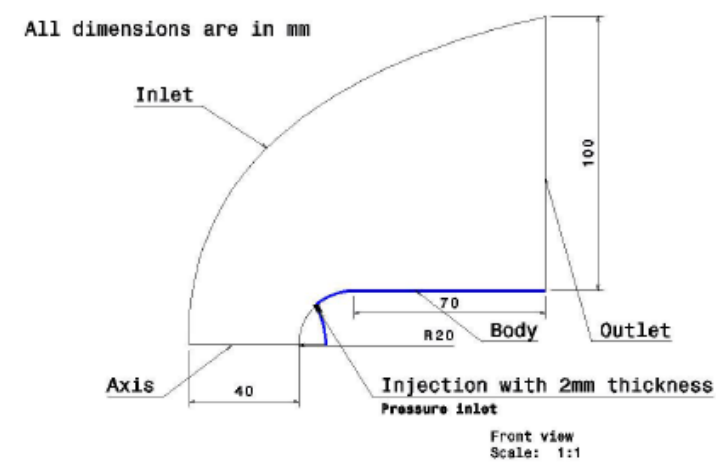

Fig. 5: Blunt Body with Forward Facing Cavity and Injection

The above geometry is the case of a blunt body having forward facing cavity and opposing jet. The dimensions are briefly mentioned in the above figure

L- Overall length of the body $(70 \mathrm{~mm})$

D- Base diameter of the body $(40 \mathrm{~mm})$

$\mathrm{r}$ - Lip radius

d- Depth of the cavity

P- Pressure of the jet stream

The values of r/d were chosen to be 1,2 and 2.5 and the values of d were taken to $4,6,8,10 \mathrm{~mm}$.

\section{MESH GENERATION}

To generate a mesh in the geometry, edges of the base body geometry are selected in the mesh tool pad. According to the First-line method, edge mesh command is later selected to create nodes on the edge of the geometry. The required face of the domain geometry is selected to create small elements.

The following pictures are the mesh created for blunt body and different cases for a blunt body having a forward facing cavity.

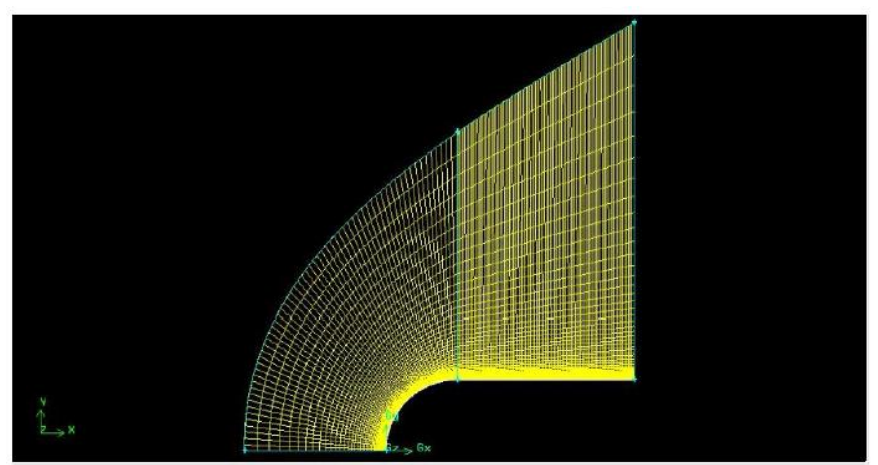

Fig. 6: Mesh Generation for a Blunt Body 


\section{Case 2:}

After generating geometry for a blunt body with a forward facing cavity, the ratio of length to diameter is varied from 1 , 2 and 2.5 for various depths of cavity ranging from $4,6,8$ and 10 as shown:

TABLE 1: VARIOUS CASES FOR A BLUNT BODY WITH FORWARD FACING CAVITY

\begin{tabular}{|c|c|c|}
\hline S.No & Depth & r/d ratio \\
\hline 1 & Blunt body & - \\
\hline 2 & 4 & 1 \\
\hline 3 & 4 & 2.5 \\
\hline 4 & 4 & 1 \\
\hline 5 & 6 & 2 \\
\hline 6 & 6 & 2.5 \\
\hline 7 & 6 & 1 \\
\hline 8 & 8 & 2 \\
\hline 9 & 8 & 2.5 \\
\hline 10 & 8 & 1 \\
\hline 11 & 10 & 2 \\
\hline 12 & 10 & 2.5 \\
\hline 13 & 10 & \\
\hline
\end{tabular}

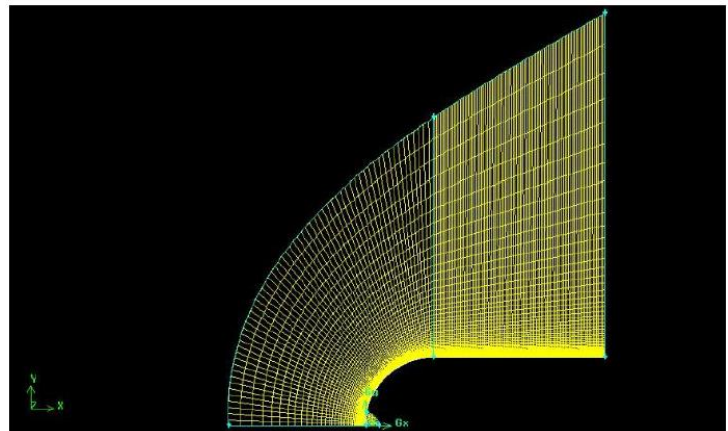

Fig. 7: Mesh Generation for a Blunt Body with $4 \mathrm{~mm}$ cavity and having r/d ratio 1

Case 3: In the following case, the blunt body having a forward facing cavity of $10 \mathrm{~mm}$ is selected as this shows the best results for heat reduction. A jet was introduced at three points on the body

- Tip

- Middle

- Centre of the cavity

The meshed files for these cases are as shown below.

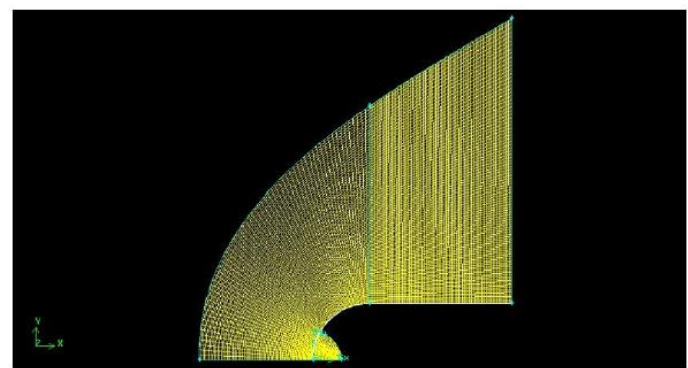

Fig. 8: Mesh Generation for a Blunt Body with $10 \mathrm{~mm}$ cavity and having jet introduced at the lip

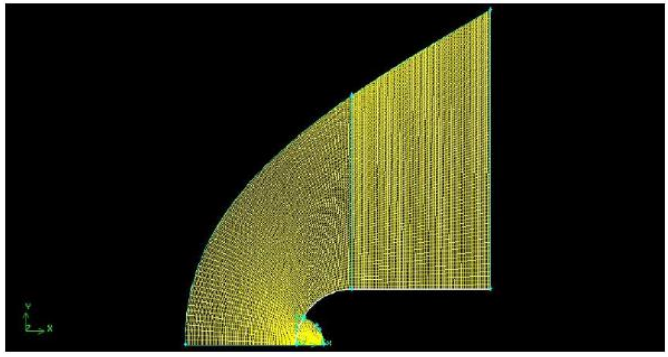

Fig. 9: Mesh Generation for a Blunt Body with 10mm cavity and having jet introduced at middle

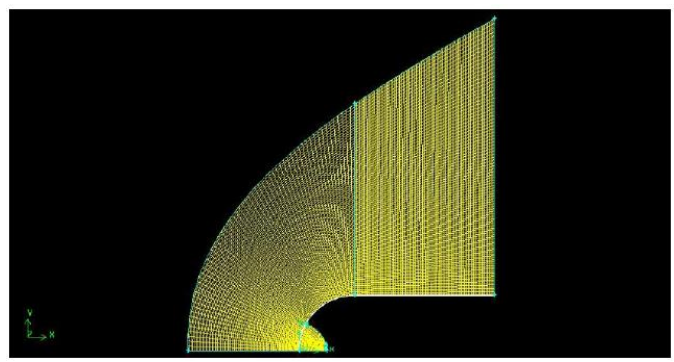

Fig. 10: Mesh Generation for a Blunt Body with $10 \mathrm{~mm}$ cavity and having jet introduced at Centre of the cavity

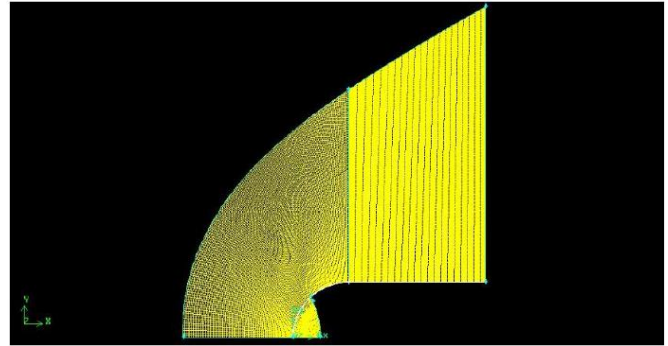

Fig. 11: Mesh Generation for a Blunt Body with $10 \mathrm{~mm}$ cavity $(\mathrm{r} / \mathrm{d}=2)$ having jet introduced at lip

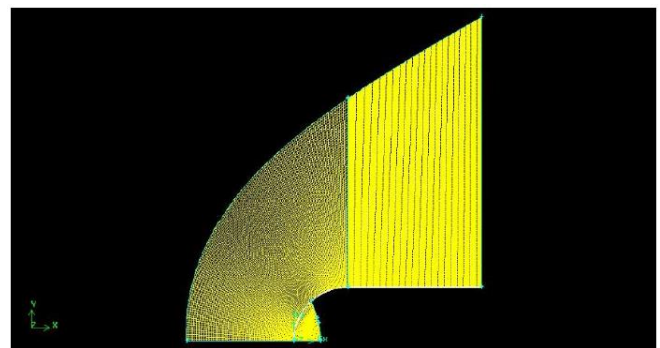

Fig. 12: Mesh Generation for a Blunt Body with $10 \mathrm{~mm}$ cavity(r/d=2) having jet introduced at middle

\section{QUALITY OF MESH}

After the mesh is generated, the quality of the mesh has to be checked.

- The type of mesh generated is a structured mesh. For the body and domain, the mesh is a quad structure. In the case of a cavity, it is a tri primitive structure

- $\quad$ The skewness ratio is 0.4 .

- $\quad$ The Growth rate is 0.0001 .

\section{E. SOLVER}

The next step in CFD analysis is Solver. In this step, all the boundary conditions and necessary required conditions for the problem statement are given as inputs in the solver setup. They are mentioned as follows: 
1. Type: density-based

2. Axis symmetric

3. Energy: on

4. Viscous: Spalart Allmaras

5. Density: ideal gas

6. Property: air

7. $\mathrm{C}_{\mathrm{p}}$ : piecewise polynomial

8. Thermal conductivity: kinetic theory

9. Viscosity: Sutherland

10. Flux type: AUSM (advection upstream splitting method)

11. Gradient: green gauss cell-based

12. Flow: second-order upwind

\section{F. BOUNDARY CONDITIONS}

1. Operating pressure: 0 pa

2. Absolute pressure: 16066 pa

\section{a. Inlet:}

1. Mach no $=6.2$

2. Average Temperature $=-56.35$ Degree Celsius or $216.65 \mathrm{~K}$

3. Pressure $=16066 \mathrm{~N} / \mathrm{m}^{2}$

4. $\rho=0.258 \mathrm{~kg} / \mathrm{m}^{3}$

5. $\mu=1.435 \times 10^{-6} \times \frac{T^{1.5}}{T+110.4}=1.789 \times 10^{-5} \mathrm{~N} \frac{\mathrm{m}}{\mathrm{s}}$

6. $R e=0.258 \times 90 \times 10^{-3} \times \frac{1829.012}{1.739} \times 10^{5}=2442188.53$

7. $a=\sqrt{\gamma R T}=\sqrt{1.4 \times 287 \times 216.65}=340.47 \mathrm{~m} / \mathrm{s}$

8. Reference area: $0.001256 \mathrm{~m}^{2}$

9. Velocity $=1829.26 \mathrm{~m} / \mathrm{s}$

\section{b. Outlet:}

1. Temperature: $216.65 \mathrm{~K}$

These boundary conditions are the same and applied for all the cases of blunt body, blunt body with forward facing cavity and blunt body with forward facing cavity with opposing jet combination.

For the case of jet injection, we use pressure injection and we calculate the injection pressure by using the following terms:

1. $P_{\infty}=16066$ Pascal

2. $M=6.2$

3. $\frac{P_{0}}{P_{\infty}}=\left(1+\frac{\gamma-1 * M_{\infty}^{2}}{2}\right)^{\frac{\gamma}{\gamma-1}}$ where $\gamma=1.4$

4. $P_{0}=31054683.36$

5. $\frac{P_{0_{\text {injection }}}}{P_{0 \infty}}=$ Pressure Ratio $(\mathrm{PR})$

6. Here the values of PR are taken as 0.025 and 0.05

7. $\frac{P_{\text {oinjection }}}{P_{\text {injection }}}=\left(1+\frac{(\gamma-1) * M_{\infty}^{2}}{2}\right)^{\frac{\gamma}{\gamma-1}}$

8. $\frac{T_{0}}{T}=\left(1+\frac{(\gamma-1) * M_{\infty}^{2}}{2}\right)$

\section{G. RESULTS AND DISCUSSIONS}

a. Blunt Body

The results for the blunt body when exposed to the working fluid are as shown:

TABLE 2: BLUNT BODY RESULTS

\begin{tabular}{|c|c|c|c|c|c|}
\hline S.No & $\begin{array}{c}\text { Depth d } \\
(\mathbf{m m})\end{array}$ & $\begin{array}{c}\text { Drag } \\
(\mathbf{N})\end{array}$ & $\begin{array}{c}\text { Total Drag } \\
\text { Coefficient } \\
\left(\boldsymbol{C}_{\mathrm{d}}\right)\end{array}$ & $\begin{array}{c}\text { Heat } \\
\text { Transfer } \\
\text { Rate }(\mathbf{W})\end{array}$ & $\begin{array}{c}\text { Peak Heat } \\
\text { Flux } \\
\left(\mathbf{W} / \mathbf{m}^{2}\right)\end{array}$ \\
\hline 1 & Blunt & 492.00514 & 0.90649804 & 10111.566 & -7189401.5 \\
\hline
\end{tabular}

\section{b. Blunt Body with Forward Facing Cavity}

Case 1: The results for the blunt body with a forward facing cavity having $\mathrm{r} / \mathrm{d}=1$ are as shown. We can see that the drag reduces as the depth of the cavity is increased. This is given in the form of the percentage change in heat transfer and Peak heat flux when compared to a normal bunt body.

Table 3: Results for $\mathrm{r} / \mathrm{d}=1$ for Blunt Body with Forward Facing Cavity

\begin{tabular}{|c|c|c|c|c|c|}
\hline S.No & $\begin{array}{c}\text { Depth d } \\
\text { (mm) }\end{array}$ & $\begin{array}{c}\text { Drag } \\
(\mathbf{N})\end{array}$ & $\begin{array}{c}\text { Total Drag } \\
\text { Coefficient } \\
\left(C_{\mathrm{d}}\right) \\
\end{array}$ & $\begin{array}{c}\text { Heat } \\
\text { Transfer } \\
\text { Rate }(W) \\
\end{array}$ & $\begin{array}{c}\text { Peak Heat } \\
\text { Flux } \\
\left(\mathbf{W} / \mathbf{m}^{2}\right)\end{array}$ \\
\hline 1 & 4 & $\begin{array}{c}491.85952 \\
(0.029 \%)\end{array}$ & $\begin{array}{c}0.90622974 \\
(0.029 \%) \\
\end{array}$ & $\begin{array}{c}-10123.259 \\
(-0.12 \%) \\
\end{array}$ & $\begin{array}{l}-4757755 \\
(33.82 \%) \\
\end{array}$ \\
\hline 2 & 6 & $\begin{array}{c}490.55664 \\
(0.29 \%)\end{array}$ & $\begin{array}{c}0.90382923 \\
(0.29 \%)\end{array}$ & $\begin{array}{c}-10183.554 \\
(-0.71 \%)\end{array}$ & $\begin{array}{c}-4451855.5 \\
(38 \%)\end{array}$ \\
\hline 3 & 8 & $\begin{array}{c}483.73431 \\
(1.64 \%) \\
\end{array}$ & $\begin{array}{c}0.89125939 \\
(1.64 \%) \\
\end{array}$ & $\begin{array}{c}-9733.4899 \\
(3.45 \%) \\
\end{array}$ & $\begin{array}{l}-4093048 \\
(45.90 \%) \\
\end{array}$ \\
\hline 4 & 10 & $\begin{array}{c}482.61461 \\
(1.90 \%)\end{array}$ & $\begin{array}{c}0.88919639 \\
(1.90 \%)\end{array}$ & $\begin{array}{c}-9001.3103 \\
(10.98 \%)\end{array}$ & $\begin{array}{c}-3720792 \\
(48.24 \%) \\
\end{array}$ \\
\hline
\end{tabular}

Case 2: The results for the blunt body with a forward facing cavity having $\mathrm{r} / \mathrm{d}=2$ are as shown. We can see that the drag reduces until a certain point and starts to increase beyond that. The percentage change of heat transfer and peak heat flux increases on comparing with a normal blunt body.

Table 4: Results for $\mathrm{r} / \mathrm{d}=2$ for Blunt Body with Forward Facing Cavity

\begin{tabular}{|c|c|c|c|c|c|}
\hline S.No & $\begin{array}{c}\text { Depth d } \\
(\mathbf{m m})\end{array}$ & $\begin{array}{c}\text { Drag } \\
(\mathbf{N})\end{array}$ & $\begin{array}{c}\text { Total Drag } \\
\text { Coefficient } \\
\left(\boldsymbol{C}_{\mathrm{d}}\right)\end{array}$ & $\begin{array}{c}\text { Heat } \\
\text { Transfer } \\
\text { Rate }(\mathbf{W})\end{array}$ & $\begin{array}{c}\text { Peak Heat } \\
\text { Flux } \\
\left(\mathbf{W} / \mathbf{m}^{2}\right)\end{array}$ \\
\hline 1 & 4 & $\begin{array}{c}488.62653 \\
(0.68 \%)\end{array}$ & $\begin{array}{c}0.90027309 \\
(0.68 \%)\end{array}$ & $\begin{array}{c}-9926.7171 \\
(1.82 \%)\end{array}$ & $\begin{array}{c}-7885392.5 \\
(-9.68 \%)\end{array}$ \\
\hline 2 & 6 & $\begin{array}{c}483.23646 \\
(1.78 \%)\end{array}$ & $\begin{array}{c}0.89034212 \\
(1.78 \%)\end{array}$ & $\begin{array}{c}-9425.091 \\
(6.78 \%)\end{array}$ & $\begin{array}{c}-7127353 \\
(0.86 \%)\end{array}$ \\
\hline 3 & 8 & $\begin{array}{c}503.44778 \\
(-2.32 \%)\end{array}$ & $\begin{array}{c}0.92787611 \\
(-2.32 \%)\end{array}$ & $\begin{array}{c}-8739.0962 \\
(13.57 \%)\end{array}$ & $\begin{array}{c}-6944527.5 \\
(3.40 \%)\end{array}$ \\
\hline 4 & 10 & $\begin{array}{c}546.90089 \\
(-10.56 \%)\end{array}$ & $\begin{array}{c}1.0076411 \\
(-10.56 \%)\end{array}$ & $\begin{array}{c}-8256.5435 \\
(17.56 \%)\end{array}$ & $\begin{array}{c}-6526192.5 \\
(9.76 \%)\end{array}$ \\
\hline
\end{tabular}

Case 3: The results for the blunt body with a forward facing cavity having $\mathrm{r} / \mathrm{d}=2.5$ are as shown. The percentage change of heat transfer and peak heat flux increases on comparing with a normal blunt body.

Table 5: Results for $\mathrm{r} / \mathrm{d}=2.5$ for Blunt Body with Forward Facing Cavity

\begin{tabular}{|c|c|c|c|c|c|}
\hline S.No & $\begin{array}{c}\text { Depth d } \\
(\mathbf{m m})\end{array}$ & $\begin{array}{c}\text { Drag } \\
(\mathbf{N})\end{array}$ & $\begin{array}{c}\text { Total Drag } \\
\text { Coefficient } \\
\left(\boldsymbol{C}_{\mathrm{d}}\right)\end{array}$ & $\begin{array}{c}\text { Heat } \\
\text { Transfer } \\
\text { Rate }(\mathbf{W})\end{array}$ & $\begin{array}{c}\text { Peak Heat } \\
\text { Flux } \\
\left(\mathbf{W} / \mathbf{m}^{2}\right)\end{array}$ \\
\hline \multirow{2}{*}{1} & 4 & $\begin{array}{c}488.44079 \\
(0.72 \%)\end{array}$ & $\begin{array}{c}0.89993087 \\
(0.72 \%)\end{array}$ & $\begin{array}{c}-9787.7987 \\
(3.2 \%)\end{array}$ & $\begin{array}{c}-7422774 \\
(-3.24 \%)\end{array}$ \\
\hline \multirow{2}{*}{2} & 6 & $\begin{array}{c}490.91615 \\
(0.22 \%)\end{array}$ & $\begin{array}{c}0.90449161 \\
(0.22 \%)\end{array}$ & $\begin{array}{c}-9236.7527 \\
(8.65 \%)\end{array}$ & $\begin{array}{c}-7358064 \\
(-2.34 \%)\end{array}$ \\
\hline 3 & 8 & $\begin{array}{c}518.68253 \\
(-5.42 \%)\end{array}$ & $\begin{array}{c}0.95564997 \\
(5.42 \%)\end{array}$ & $\begin{array}{c}-8741.9706 \\
(13.54 \%)\end{array}$ & $\begin{array}{c}-6976395.5 \\
(2.96 \%)\end{array}$ \\
\hline 4 & 10 & $\begin{array}{c}588.20215 \\
(-20.31 \%)\end{array}$ & $\begin{array}{c}1.0837368 \\
(-20.31 \%)\end{array}$ & $\begin{array}{c}-8245.0856 \\
(18.81 \%)\end{array}$ & $\begin{array}{c}-6738175.5 \\
(7.38 \%)\end{array}$ \\
\hline
\end{tabular}


Comparing the above results and plotting in the form of graph. We get it as shown below.

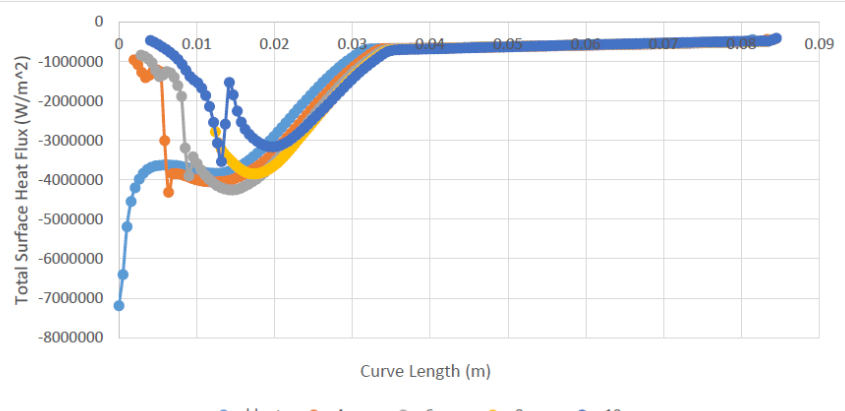

Graph 1: Total Surface Heat vs Curve Length For $\mathrm{r} / \mathrm{d}=1$

From the above graph, we see that the Blunt Body has maximum heat at the surface which is decreased in $4 \mathrm{~mm}$, $6 \mathrm{~mm}, 8 \mathrm{~mm}$ and $10 \mathrm{~mm}$. This shows that as the depth of the cavity increases the amount of the surface heat flux decreases. Further, the surface heat becomes constant as we move from left to right across the geometry.

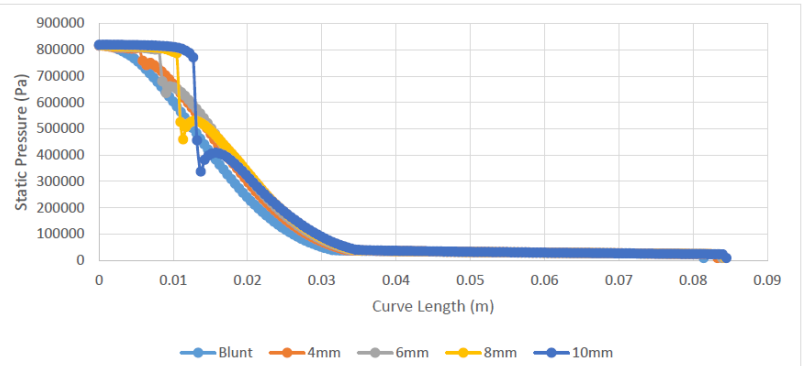

Graph 2: Static Pressure vs Curve Length for $\mathrm{r} / \mathrm{d}=1$

As we move from left to right the static pressure decreases along the cavity and increases at the lip of the cavity and then becomes constant along the blunt body. As the depth of the cavity increases the value of static pressure is less.

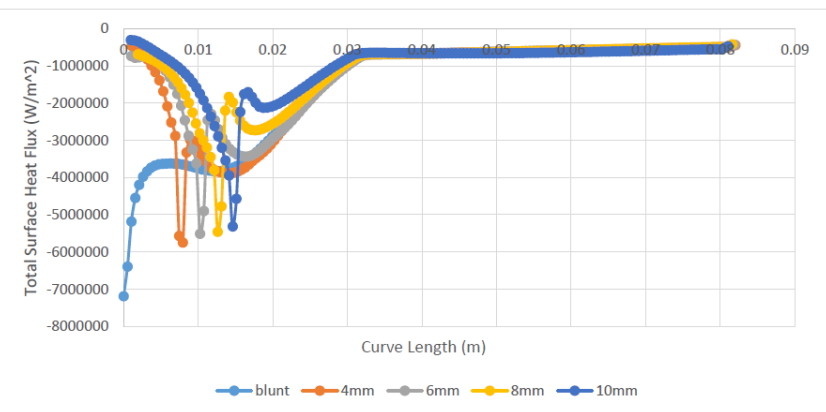

Graph 3: Total Surface Heat Flux vs Curve Length for $r / d=2$

From the above graph as Blunt Body having maximum Heat at the surface which is decreased in $4 \mathrm{~mm}, 6 \mathrm{~mm}, 8 \mathrm{~mm}$ and $10 \mathrm{~mm}$. This shows that as the depth of the cavity increases the amount of the surface heat flux decreases. Further, the surface heat becomes constant as we move from left to right across the geometry.

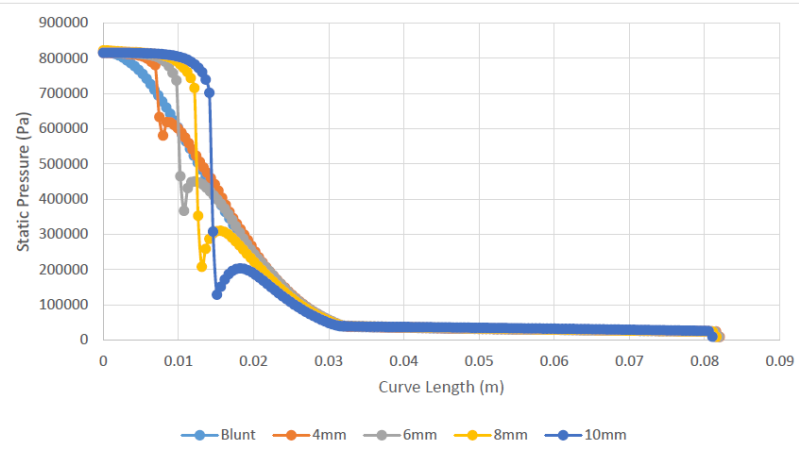

Graph 4: Static Pressure vs Curve Length for $\mathrm{r} / \mathrm{d}=2$

From the above graph, as we move from left to right the static pressure decreases along the cavity and increases a little at the lip of the cavity and then becomes constant along the blunt body. As the depth of the cavity increases the value of static pressure is less.

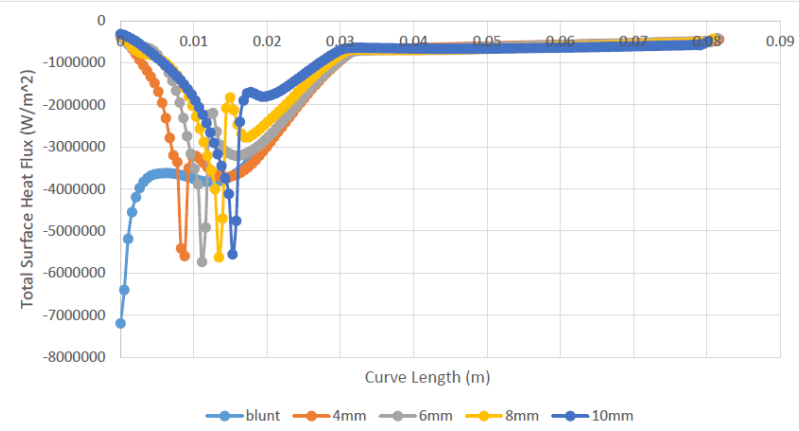

Graph 5: Total Surface Heat Flux vs. Curve Length for r/d=2.5

Blunt Body having maximum Heat at the surface which is decreased in $4 \mathrm{~mm}, 6 \mathrm{~mm}, 8 \mathrm{~mm}$ and $10 \mathrm{~mm}$. This shows that as the depth of the cavity increases the amount of the surface heat flux decreases. The surface heat becomes constant as we move from left to right across the geometry.

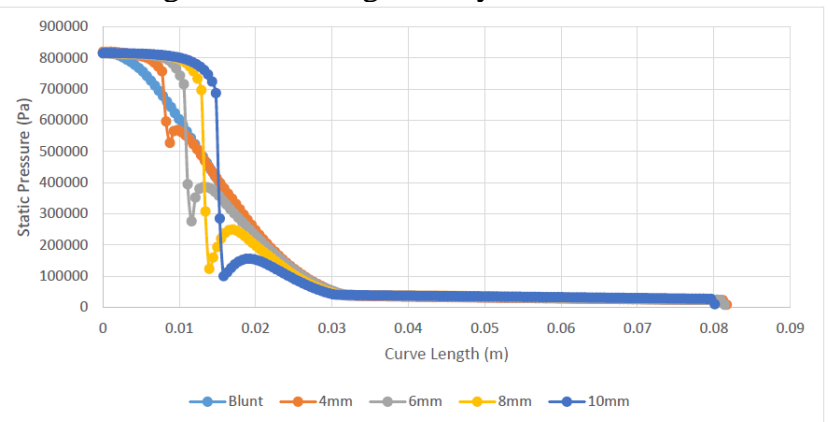

Graph 6: Static Pressure vs Curve Length for $\mathrm{r} / \mathrm{d}=2.5$

As we move from left to right the static pressure decreases along the cavity and increases a little at the lip of the cavity and then becomes constant along the blunt body. As the depth of the cavity increases the value of static pressure is less.

\section{c. Best Result}

From all the above cases, the best results are obtained for a blunt body with a cavity having a depth of $10 \mathrm{~mm}$. So plotting individually the results for different $1 / \mathrm{d}$ ratios we get the following graph. 


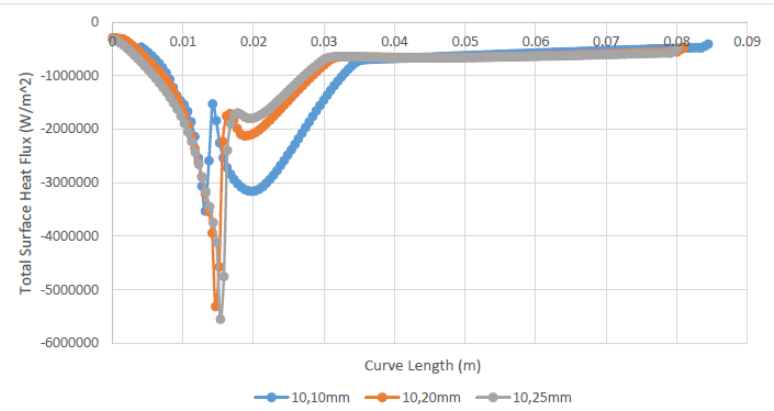

Graph 7: Total Surface Heat Flux vs Curve Length for 10mm depth

We can observe that as the value of radius increase from 10 to $25 \mathrm{~mm}$ there is a reduction in total surface heat flux at the cavity and goes to approximately the same value along the surface.

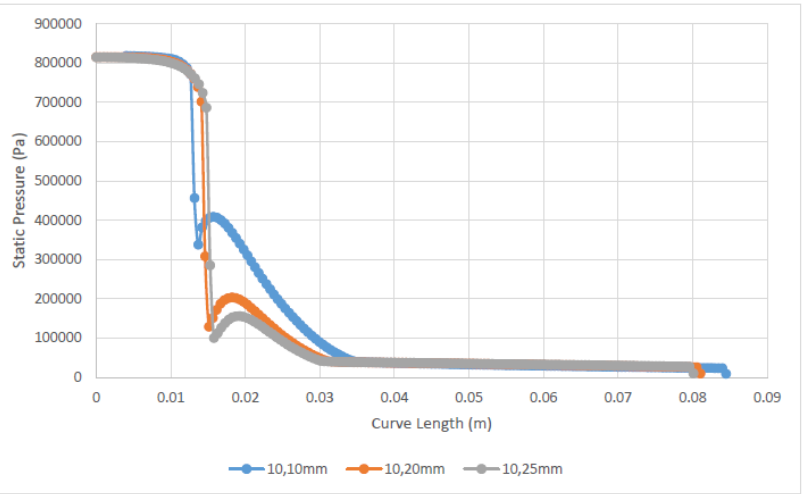

Graph 8: Static Pressure vs Curve Length for 10mm depth

From the above graph as we move from 10 to $25 \mathrm{~mm}$ in radius the value of static pressure decreases.

\section{H. VARIATION OF CONTOURS}

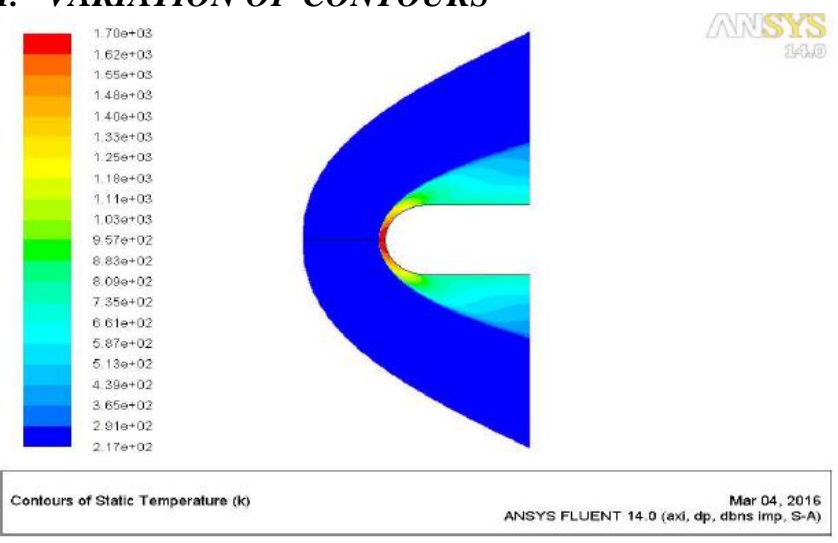

Fig. 13: Variation of Static Temperature across blunt body

From the above figure, we can see that the static temperature is maximum at the nose and decreases gradually around the body.

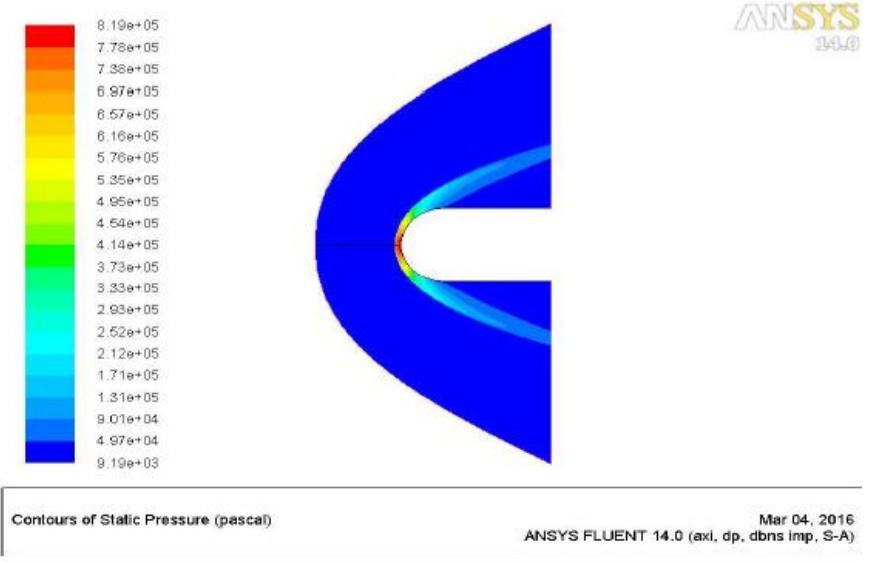

Fig. 14: Variation of Static Pressure across Blunt Body

Here we see that that the static pressure is maximum at the nose of the body and decreases gradually.
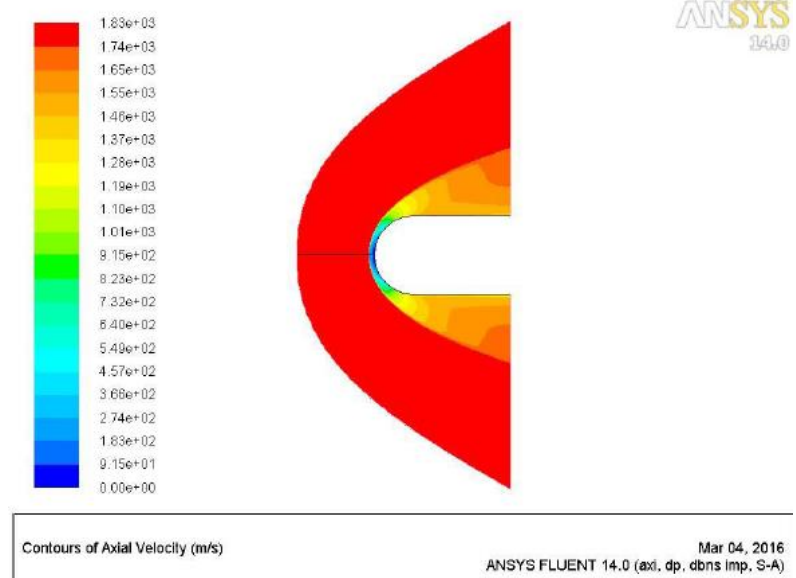

Fig. 15: Variation of Axial Velocity across blunt body

From the figure, we see that the minimum velocity is attained at the nose of the body due to its high pressure.

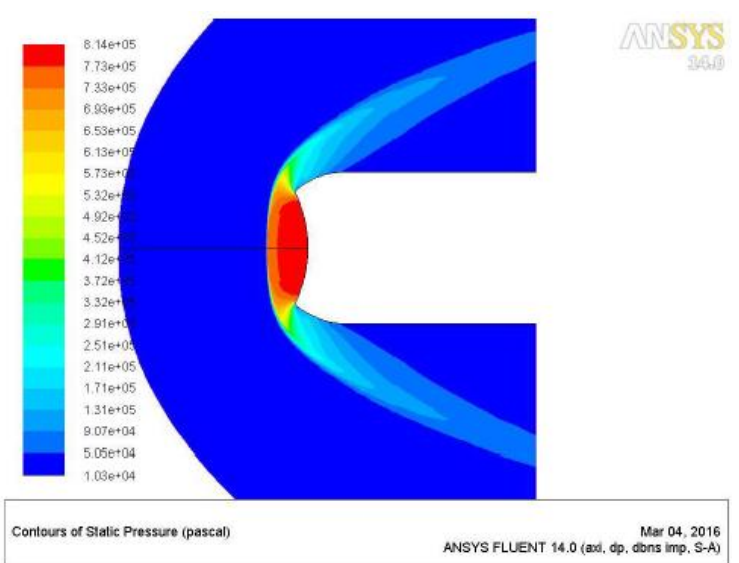

Fig. 16: Variation of static pressure across blunt body with $10 \mathrm{~mm}$ cavity 


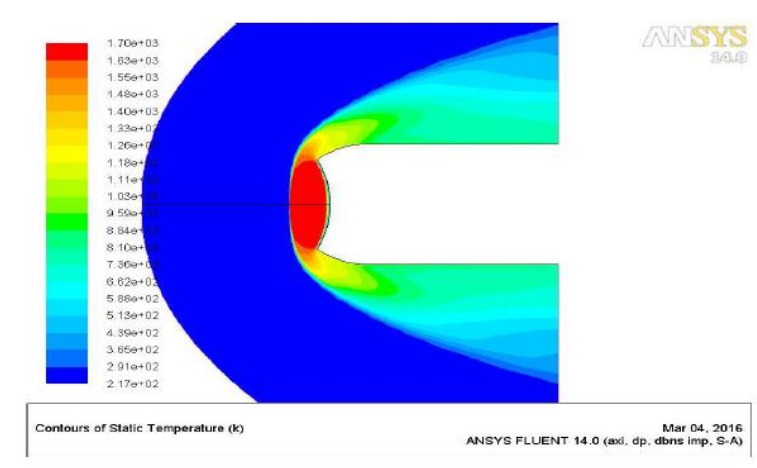

Fig. 17: Variation of static temperature across blunt body with $10 \mathrm{~mm}$ cavity

From the above figure, we can see that the static temperature decreases gradually around the body due to generation of circulation region.

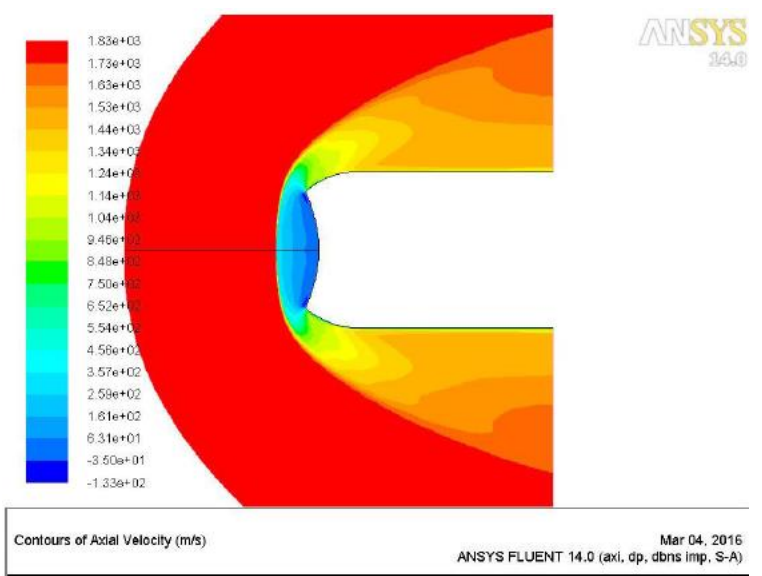

Fig. 18: Variation of axial velocity across blunt body with $10 \mathrm{~mm}$ cavity

From the figure, we see that the minimum velocity is attained at the nose of the body due to its high pressure.

\section{BLUNT BODY WITH FORWARD FACING CAVITY AND OPPOSING JET}

The results for the blunt body with forward facing cavity with a $10 \mathrm{~mm}$ cavity turned out to be more productive. Now we introduce opposing jet at three different locations on the body and we obtain the results for different pressure ratios as shown:

Table 6: Results for a blunt body with $10 \mathrm{~mm}$ cavity $(\mathrm{r} / \mathrm{d}=1)$ with opposing jet and having pressure ratio 0.05

\begin{tabular}{|c|c|c|c|c|}
\hline \multirow{2}{*}{ Location } & $\begin{array}{c}\text { Drag } \\
(\mathbf{N})\end{array}$ & $\begin{array}{c}\text { Total Drag } \\
\text { Coefficient } \\
\left(\boldsymbol{C}_{\mathrm{d}}\right)\end{array}$ & $\begin{array}{c}\text { Heat } \\
\text { Transfer } \\
\text { Rate }(\mathbf{W})\end{array}$ & $\begin{array}{c}\text { Peak Heat } \\
\text { Flux }\left(\mathbf{W} / \mathbf{m}^{2}\right)\end{array}$ \\
\hline \multirow{2}{*}{ Tip } & $\begin{array}{c}191.3251107 \\
(29.66 \%)\end{array}$ & $\begin{array}{c}0.353038926 \\
(29.66 \%)\end{array}$ & $\begin{array}{c}59.76784756 \\
(40.18 \%)\end{array}$ & $\begin{array}{c}-7130.461495 \\
(42.40 \%)\end{array}$ \\
\hline \multirow{2}{*}{ Middle } & $\begin{array}{c}188.73525 \\
(30.86 \%)\end{array}$ & $\begin{array}{c}0.34826004 \\
(30.86 \%)\end{array}$ & $\begin{array}{c}57.294601 \\
(42.77 \%)\end{array}$ & $\begin{array}{c}-6228.6968 \\
(43.49 \%)\end{array}$ \\
\hline \multirow{2}{*}{ Cavity } & $\begin{array}{c}188.2275891 \\
(30.90 \%)\end{array}$ & $\begin{array}{c}0.347323287 \\
(30.90 \%)\end{array}$ & $\begin{array}{c}52.82919321 \\
(45.74 \%)\end{array}$ & $\begin{array}{c}-5959.529479 \\
(45.41 \%)\end{array}$ \\
\hline
\end{tabular}

Table 7: Results for a blunt body with $10 \mathrm{~mm}$ cavity $(\mathrm{r} / \mathrm{d}=2)$ with opposing jet and having pressure ratio 0.05

\begin{tabular}{|c|c|c|c|c|}
\hline \multirow{2}{*}{ Location } & $\begin{array}{c}\text { Drag } \\
(\mathbf{N})\end{array}$ & $\begin{array}{c}\text { Total Drag } \\
\text { Coefficient } \\
\left(\boldsymbol{C}_{\mathrm{d}}\right)\end{array}$ & $\begin{array}{c}\text { Heat } \\
\text { Transfer } \\
\text { Rate }(\mathbf{W})\end{array}$ & $\begin{array}{c}\text { Peak Heat } \\
\text { Flux }\left(\mathbf{W} / \mathbf{m}^{2}\right)\end{array}$ \\
\hline \multirow{2}{*}{ Tip } & $\begin{array}{c}188.4701208 \\
(30.89 \%)\end{array}$ & $\begin{array}{c}0.3477770813 \\
(30.89 \%)\end{array}$ & $\begin{array}{c}55.31638583 \\
(40.75 \%)\end{array}$ & $\begin{array}{c}-11415.76049 \\
(45.35 \%)\end{array}$ \\
\hline Middle & $\begin{array}{c}1.040361385 \\
(30.28 \%)\end{array}$ & $\begin{array}{c}1.040692821 \\
(31.1 \%)\end{array}$ & $\begin{array}{c}0.895202045 \\
(43.55 \%)\end{array}$ & $\begin{array}{c}1.785755888 \\
(44.51 \%)\end{array}$ \\
\hline Cavity & $\begin{array}{c}212.1696828 \\
(31.56 \%)\end{array}$ & $\begin{array}{c}0.391501961 \\
(31.94 \%)\end{array}$ & $\begin{array}{c}48.91954804 \\
(46.24 \%)\end{array}$ & $\begin{array}{c}-10390.82669 \\
(44.15 \%)\end{array}$ \\
\hline
\end{tabular}

Table 8: Results for a blunt body with $10 \mathrm{~mm}$ cavity $(\mathrm{r} / \mathrm{d}=2.5)$ with opposing jet and having pressure ratio 0.05

\begin{tabular}{|c|c|c|c|c|}
\hline \multirow{2}{*}{ Location } & $\begin{array}{c}\text { Drag } \\
(\mathbf{N})\end{array}$ & $\begin{array}{c}\text { Total Drag } \\
\text { Coefficient } \\
\left(\boldsymbol{C}_{\mathbf{d}}\right)\end{array}$ & $\begin{array}{c}\text { Heat } \\
\text { Transfer } \\
\text { Rate }(\mathbf{W})\end{array}$ & $\begin{array}{c}\text { Peak Heat } \\
\text { Flux }\left(\mathbf{W} / \mathbf{m}^{2}\right)\end{array}$ \\
\hline \multirow{2}{*}{ Tip } & $\begin{array}{c}174.7605163 \\
(31.58 \%)\end{array}$ & $\begin{array}{c}0.32247344 \\
(31.56 \%)\end{array}$ & $\begin{array}{c}143.9469897 \\
(41.06 \%)\end{array}$ & $\begin{array}{c}-2136160.69 \\
(44.92 \%)\end{array}$ \\
\hline \multirow{2}{*}{ Middle } & $\begin{array}{c}184.645029 \\
(31.68 \%)\end{array}$ & $\begin{array}{c}0.34071265 \\
(31.89 \%)\end{array}$ & $\begin{array}{c}136.2362286 \\
(44.12 \%)\end{array}$ & $\begin{array}{c}-2025356.374 \\
(44.12 \%)\end{array}$ \\
\hline \multirow{2}{*}{ Cavity } & $\begin{array}{c}210.72446 \\
(32.51 \%)\end{array}$ & $\begin{array}{c}0.3888352 \\
(32.64 \%)\end{array}$ & $\begin{array}{c}127.92724 \\
(47.15 \%)\end{array}$ & $\begin{array}{c}-1933057.5 \\
(43.76 \%)\end{array}$ \\
\hline
\end{tabular}

Table 9: Results for a blunt body with $10 \mathrm{~mm}$ cavity $(\mathrm{r} / \mathrm{d}=1)$ with opposing jet and having pressure ratio 0.025

\begin{tabular}{|c|c|c|c|c|}
\hline \multirow{2}{*}{ Location } & $\begin{array}{c}\text { Drag } \\
(\mathbf{N})\end{array}$ & $\begin{array}{c}\text { Total Drag } \\
\text { Coefficient } \\
\left(\boldsymbol{C}_{\mathrm{d}}\right)\end{array}$ & $\begin{array}{c}\text { Heat Transfer } \\
\text { Rate }(\mathbf{W})\end{array}$ & $\begin{array}{c}\text { Peak Heat } \\
\text { Flux }\left(\mathbf{W} / \mathbf{m}^{2}\right)\end{array}$ \\
\hline \multirow{2}{*}{ Tip } & $\begin{array}{c}398.3079614 \\
(14.26 \%)\end{array}$ & $\begin{array}{c}0.734969999 \\
(14.26 \%)\end{array}$ & $\begin{array}{c}-918.3335574 \\
(40.25 \%)\end{array}$ & $\begin{array}{c}-1196337.211 \\
(37.55 \%)\end{array}$ \\
\hline \multirow{2}{*}{ Middle } & $\begin{array}{c}392.91629 \\
(15.65 \%)\end{array}$ & $\begin{array}{c}0.72502113 \\
(15.65 \%)\end{array}$ & $\begin{array}{c}-880.3321 \\
(40.98 \%)\end{array}$ & $\begin{array}{c}-1045040.6 \\
(37.45 \%)\end{array}$ \\
\hline \multirow{2}{*}{ Cavity } & $\begin{array}{c}391.8594221 \\
(16.15 \%)\end{array}$ & $\begin{array}{c}0.723070961 \\
(15.84 \%)\end{array}$ & $\begin{array}{c}-811.7210661 \\
(41.15 \%)\end{array}$ & $\begin{array}{c}-999880.1454 \\
(36.71 \%)\end{array}$ \\
\hline
\end{tabular}

Table 10: Results for a blunt body with $10 \mathrm{~mm}$ cavity $(\mathrm{r} / \mathrm{d}=2)$ with opposing jet and having pressure ratio 0.025

\begin{tabular}{|c|c|c|c|c|}
\hline \multirow{2}{*}{ Location } & $\begin{array}{c}\text { Drag } \\
(\mathbf{N})\end{array}$ & $\begin{array}{c}\text { Total Drag } \\
\text { Coefficient } \\
\left(\boldsymbol{C}_{\mathrm{d}}\right)\end{array}$ & $\begin{array}{c}\text { Heat Transfer } \\
\text { Rate }(\mathbf{W})\end{array}$ & $\begin{array}{c}\text { Peak Heat } \\
\text { Flux }\left(\mathbf{W} / \mathbf{m}^{2}\right)\end{array}$ \\
\hline \multirow{2}{*}{ Tip } & $\begin{array}{c}392.3643338 \\
(15.15 \%)\end{array}$ & $\begin{array}{c}0.724002638 \\
(14.78 \%)\end{array}$ & $\begin{array}{c}-849.9368047 \\
(40.72 \%)\end{array}$ & $\begin{array}{c}-1915317.694 \\
(37.11 \%)\end{array}$ \\
\hline \multirow{2}{*}{ Middle } & $\begin{array}{c}1.040361385 \\
(15.90 \%)\end{array}$ & $\begin{array}{c}1.040692821 \\
(15.67 \%)\end{array}$ & $\begin{array}{c}0.895202045 \\
(41.58 \%)\end{array}$ & $\begin{array}{c}1.785755888 \\
(36.81 \%)\end{array}$ \\
\hline \multirow{2}{*}{ Cavity } & $\begin{array}{c}441.7029919 \\
(16.57 \%)\end{array}$ & $\begin{array}{c}0.815043822 \\
(16.21 \%)\end{array}$ & $\begin{array}{c}-751.6493301 \\
(42.14 \%)\end{array}$ & $\begin{array}{c}-1743355.971 \\
(35.18 \%)\end{array}$ \\
\hline
\end{tabular}

Table 11: Results for a blunt body with $10 \mathrm{~mm}$ cavity $(\mathrm{r} / \mathrm{d}=2.5)$ with opposing jet and having pressure ratio 0.025

\begin{tabular}{|c|c|c|c|c|}
\hline Location & $\begin{array}{c}\text { Drag } \\
(\mathbf{N})\end{array}$ & $\begin{array}{c}\text { Total Drag } \\
\text { Coefficient } \\
\left(\boldsymbol{C}_{\mathrm{d}}\right)\end{array}$ & $\begin{array}{c}\text { Heat Transfer } \\
\text { Rate }(\mathbf{W})\end{array}$ & $\begin{array}{c}\text { Peak Heat } \\
\text { Flux }\left(\mathbf{W} / \mathbf{m}^{2}\right)\end{array}$ \\
\hline \multirow{2}{*}{ Tip } & $\begin{array}{c}378.5022597 \\
(16.76 \%)\end{array}$ & $\begin{array}{c}0.698423927 \\
(15.28 \%)\end{array}$ & $\begin{array}{c}-345.8186404 \\
(41.58 \%)\end{array}$ & $\begin{array}{c}-141752.7771 \\
(36.27 \%)\end{array}$ \\
\hline \multirow{2}{*}{ Middle } & $\begin{array}{c}399.9104729 \\
(16.41 \%)\end{array}$ & $\begin{array}{c}0.737927027 \\
(16.61 \%)\end{array}$ & $\begin{array}{c}-327.2942868 \\
(42.51 \%)\end{array}$ & $\begin{array}{c}-134399.9503 \\
(35.91 \%)\end{array}$ \\
\hline \multirow{2}{*}{ Cavity } & $\begin{array}{c}456.39419 \\
(17.54 \%)\end{array}$ & $\begin{array}{c}0.84215248 \\
(17.64 \%)\end{array}$ & $\begin{array}{c}-307.33275 \\
(43.84 \%)\end{array}$ & $\begin{array}{c}-128275.12 \\
(34.84 \%)\end{array}$ \\
\hline
\end{tabular}

The results are now plotted as shown below:

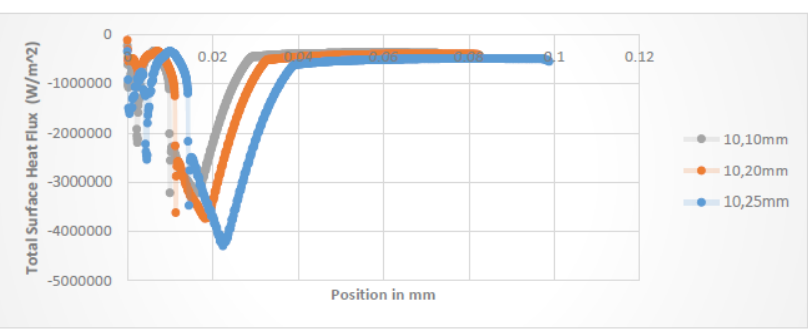

Graph 9: Total Surface Heat Flux vs. Curve Length for 10mm Cavity

As we move from 10 to $25 \mathrm{~mm}$ in radius the value of heat flux on tip decreases. 


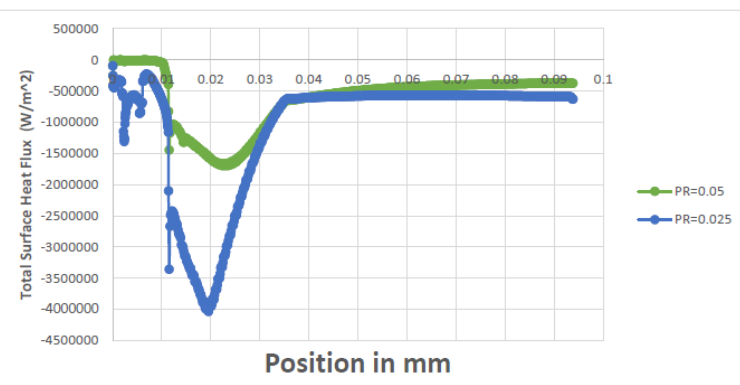

Graph 10: Total Surface Heat Flux vs. Curve Length for 10,25mm

As we move from $\mathrm{PR}=0.025$ to 0.05 the value of heat flux on surface decrease as the injection pressure cools the region around it.

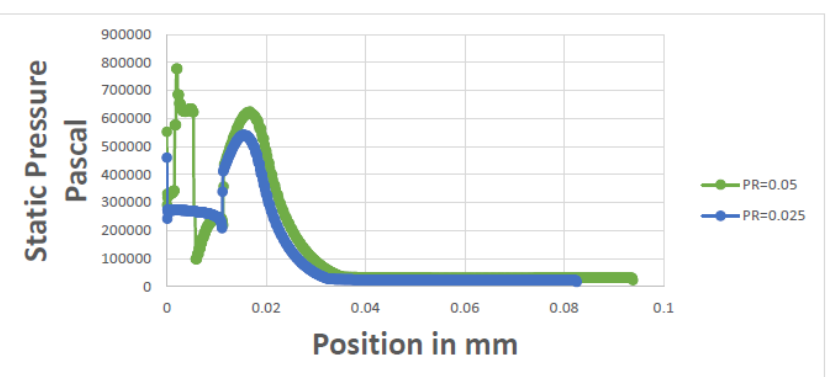

Graph 11: Static Pressure vs. Curve Length for $10,25 \mathrm{~mm}$

As we move from $P R=0.025$ to 0.05 the value of Pressure on the surface increases.

\section{A. Contours for blunt body with injection at the center which gives us the best result}

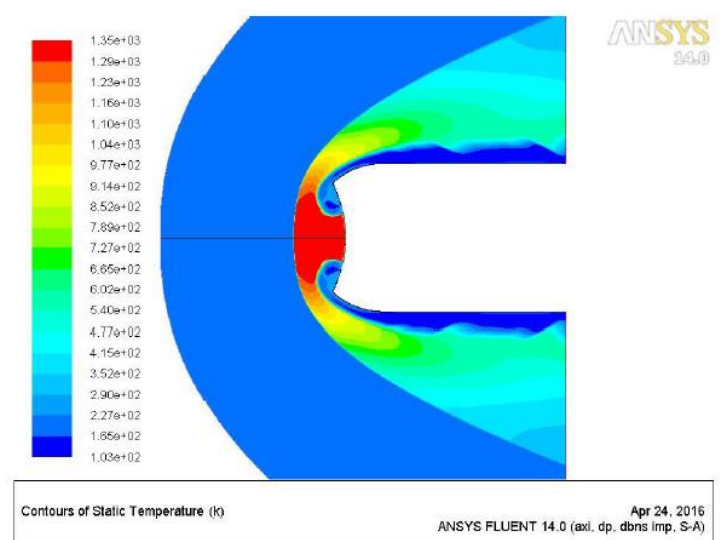

Fig. 19: Static Temperature Variation

At the cavity, as the depth increases and the PR increases the temperature in the cavity decreases and it increases slightly at the lip and then keeps on decreasing around the body.

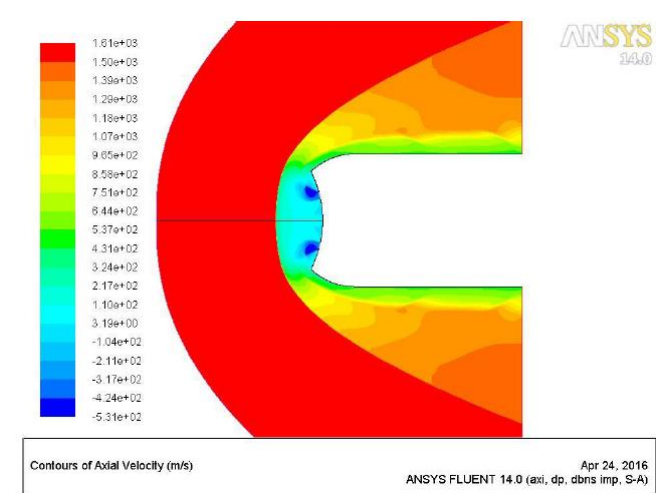

Fig. 20: Variation of Axial Velocity

Since there is an increase in the static pressure inside the cavity the velocity decreases in the cavity and then increases around the body.

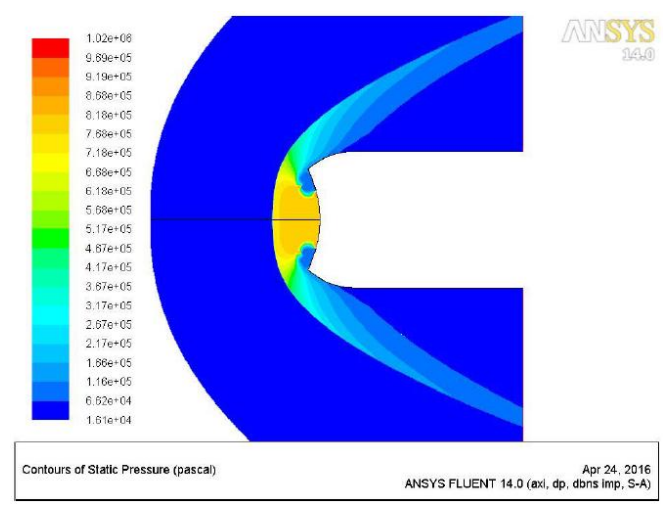

Fig. 21: Variation of Static Pressure

At the cavity, as the depth increases with PR increasing the static pressure in the cavity increases and it decreases slightly at the lip and then keeps on decreasing around the body.

\section{CONCLUSION}

From the analysis results above, it can be concluded that a blunt body using forward facing cavity would have more reduction in aerodynamic heating in the case when the r/d ratio is more and the length of the cavity is deepest. In this paper, we have compared the analysis results for different $\mathrm{r} / \mathrm{d}$ ratio of $1,2,2.5$ and length of $4 \mathrm{~mm}, 6 \mathrm{~mm}, 8 \mathrm{~mm}$ and $10 \mathrm{~mm}$. It was found that $\mathrm{r} / \mathrm{d} 2.5$ and length $10 \mathrm{~mm}$ experiences the highest reduction in aerodynamic heating i.e. the case of a blunt body having the combinational thermal protection system (forward facing cavity and opposing jet). The most important and dependent parameter for this analysis is the pressure ratio (PR) or mass flow rate. In this paper analysis based on PR varying from 0.025 to 0.05 for $10 \mathrm{~mm}$ having varying $\mathrm{r} / \mathrm{d} 1,2$, and 2.5 is done. It is proved from the results that more the value of PR, more is the heat reduction for higher $\mathrm{r} / \mathrm{d}$ ratio i.e. when $\mathrm{PR}=$ 0.05 for $10 \mathrm{~mm}$ length and $\mathrm{r} / \mathrm{d}=2.5$, the heat reduction is almost $41 \%$ at the tip, $44 \%$ at the middle and $47 \%$ at the center. 


\section{REFERENCES}

[1] Copper,M., Beckwith, I.E., Jones, J.J. and Gallagher, J.J., 1958. Heattransfer measurements on a concave hemispherical nose shape with unsteady-flow effects at Mach numbers of 1.98 and 4.95

[2] Hopko, R.N. and Strass, H.K., 1958. Some Experimental Heating Data on Convex and Concave Hemispherical Nose Shapes and Hemispherical Depressions on a 30 Deg Blunted Nose Cone.

[3] IBurbank, P.B., 1959. Heat-transfer and Pressure Measurements on Concove-nose Cylinder for a Mach Number Range of 2.49 to 4.44. National Aeronautics and Space Administration.

[4] Huebner, L.D. and Utreja, L.R., 1987. Experimental flowfield measurements of a nose cavity configuration (No. 871880). SAE Technical Paper.

[5] Sudarshan, B. and Saravanan, S., 2018. Heat flux characteristics within and outside a forward facing cavity in a hypersonic flow. Experimental Thermal and Fluid Science, 97, pp.59-69.

[6] Lu, H.B. and Liu, W.Q., 2012. Forward-facing cavity and opposing jet combined thermal protection system. Thermophysics and Aeromechanics, 19(4), pp.561-569.

[7] Hayashi, K., Aso, S. and Tani, Y., 2006. Numerical study on aerodynamic heating reduction by opposing jet. AIAA Journal, 66(1).

[8] Tamada, I., Aso, S. and Tani, Y., 2008, September. Numerical study of the effect of the opposing jet on reduction of aerodynamic heating with different nose configurations. In 26th International Congress of the Aeronautical Sciences, Anchorage, AL (pp. 14-19)

[9] Morimoto, N., Aso, S. and Tani, Y., 2014. Reduction of aerodynamic heating and drag with opposing jet through extended nozzle in high enthalpy flow. In Proceedings of the 29th Congress of the International Council of the Aeronautical Sciences, Petersburg, Russia, ICAS.

[10] Han, G. and Jiang, Z., 2018. Hypersonic flow field reconfiguration and drag reduction of blunt body with spikes and sideward jets. International Journal of Aerospace Engineering, 2018.

[11] Hutt, G.R. and Howe, A.J., 1989. Forward facing spike effects on bodies of different cross section in supersonic flow. The Aeronautical Journal, 93(926), pp.229-234.

[12] Yadav, R. and Guven, U., 2015. Aerodynamic heating of a hypersonic projectile with forward-facing ellipsoid cavity at nose. Journal of Spacecraft and Rockets, 52(1), pp.157-165.

[13] Yadav, R. and Guven, U., 2014. Aerothermodynamics of a hypersonic vehicle with a forward-facing parabolic cavity at nose. Proceedings of the Institution of Mechanical Engineers, Part G: Journal of Aerospace Engineering, 228(10), pp.1863-1 